\title{
LAS MARCAS MEDIEVALES: ETAPAS Y EVOLUCIÓN EN SU CARÁCTER COMUNICATIVO Y CONSTRUCTIVO
}

\author{
Sofía Escudero Fernández \\ Universitat Politècnica de València \\ soesfer@upv.es
}

\section{RESUMEN}

Analizamos la evolución y la generación de marcas, grafismos y el resto de elementos asociados a las marcas realizando un recorrido histórico. A través de éste, se comprende la evolución de la construcción de marcas desde el siglo $\mathrm{v}$ al xv, asociada a la evolución de las sociedades medievales, la cité y el burgo, las corporaciones y los gremios, entre otros, en la incipiente sociedad mercantil. El análisis histórico nos ayuda a dilucidar cómo el proceso constructivo y el uso de las marcas en diferentes entornos institucionales, empresariales y profesionales actuales tienen su origen en la Edad Media, pudiendo constatar que la mayoría de las variantes en el diseño de marcas que se producían en el ámbito profesional medieval siguen estando en uso como concepto constructivo.

Palabras Clave: Edad Media, diseño, marcas, representación de signos.

\author{
MEDIEVAL BRANDS: STAGES AND EVOLUTION IN \\ ITS COMMUNICATIVE AND CONSTRUCTIVE CHARACTER
}

\section{Abstract}

The paper analyses the evolution and generation of marks, graphics, and other elements linked with the brands by doing a historical tour. This allows to understand the evolution of brands construction during the $\mathrm{v}$ and $\mathrm{xV}$ centuries, associated with the evolution of medieval societies, the cité and the burgo, corporations and guilds, among others, in the emerging commercial society. This historical analysis helps us to clarify how the constructive process and the nowadays use of brands in different institutional, business and professional environments have their origins in the Middle Age. That helps us to confirm that most of the variations in brands design already presents in the medieval professional field are currently in use as constructive concept.

KeYwords: Middle Ages, design, brands, representation of signs. 


\section{INTRODUCCIÓN}

La marca en la actualidad y desde el punto de vista formal, según el Diccionario profesional de marketing, se define del siguiente modo: «Nombre, dibujos, impresiones, estampas, figuras, letras, formas de productos o envases y todos los otros signos que sirvan para distinguir los productos (bienes o servicios) de una organización»"${ }^{1}$.

Sin embargo, como veremos, los antecedentes de las marcas actuales se encuentran estrechamente enraizados en un método constructivo que se inicia en la Edad Media. En la cual se comienza a gestar el uso "corporativo» de los colores y grafismos, mediante un complejo trabajo constructivo de formas y colores que permiten identificar al portador, comunicar su estatus, el gremio, el profesional e incluso la herencia profesional-familiar mediante el brisado. Métodos que irán evolucionando a medida que se desarrollan los sistemas sociales y los entornos de uso.

\section{METODOLOGÍA}

El presente artículo muestra el complejo proceso y evolución de las marcas de la Edad Media. Proceso que, como veremos, está estrechamente enraizado en una evolución social que dará paso a unos sistemas constructivos y a unas disciplinas gráficas que se integrarán en todo tipo de soportes.

El recorrido histórico está dividido en los estudios llevados a cabo por diferentes disciplinas, las cuales han aportado claridad al sistema de creación de marcas, al uso normalizado del color e incluso de signos, y al uso de marcas de diferentes gremios, que arrojan luz sobre el empleo regulado de las mismas, así como sobre diferentes metodologías constructivas.

\section{LAS MARCAS EN LA EDAD MEDIA}

En este periodo, comprendido entre el siglo $\mathrm{v}$ y el $\mathrm{xv}$, se produce una incipiente generación de signos vinculados a la diferenciación, definición y concreción del estatus social entre personas, familias, pueblos y regiones. Este despliegue viene dado por la ciencia de la heráldica, que cifra su origen en la época feudal y, principalmente, en el periodo de las cruzadas, donde empezó a regularizarse y definirse como un arte al que se denominó blasón.

La palabra blasón tiene un origen incierto, aunque algunos autores apuntan al término latín blasus, cuyo significado es «arma de guerra $»^{2}$. Blasonar significa

1 Según lo define el Diccionario profesional de marketing (Madrid: CSIC, 1999).

2 Glosario de M. Guerard para el «Polyptique» del abad Irminon, citado en el diccionario heráldico de Charles Grandmaison, 1861. 


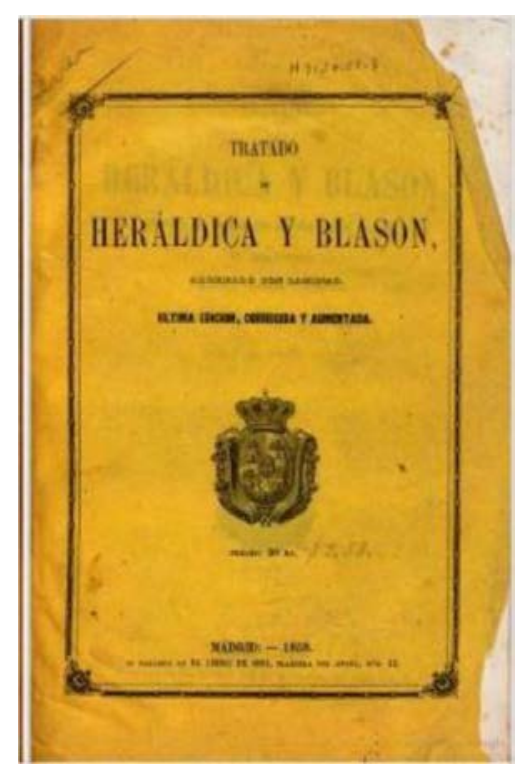

Figura 1. Libro Tratado de heráldica y blasón, adornado con láminas.

describir las armerías siguiendo las reglas de la ciencia heráldica. Francisco Piferrer en su libro Tratado de heráldica y blasón (1855) (figura 1) indica que el primero que definió las reglas del blasón fue Alejandro Magno, creando un método para el uso de las armerías e instituyendo reyes de armas o heraldos (Piferrer 1855).

Para la RAE la heráldica es la ciencia del blasón, y la define como el «arte de explicar y describir los escudos de armas de cada linaje, ciudad o persona». Si nos remitimos a una definición más próxima a la época de uso, Piferrer se refiere a la palabra blasón, en su acepción más general, como «todo signo, figura o emblema con el que se distinguen unos de otros los reinos, provincias, ciudades, pueblos, familias e individuos» (Piferrer 1855, 24). Sin embargo, igualmente indica que su origen puede situarse en las doce tribus de Israel, subrayando que ya disponían de un blasón o emblema. Así, nos muestra unos cuantos ejemplos como la tribu de Judá, que disponía de un león; o el sol y la luna, que eran los blasones de la tribu de José, entre otros. Este apunte es certificado igualmente en el libro de Pedro Joseph de Aldazaval y Murguía ${ }^{3}$ (figura 2), aunque en su caso sitúa el origen del blasón, además de en las referencias bíblicas, en el arte egipcio. E incluye como ejemplo la insignia del árbol, la serpiente y el buey, respectivamente.

3 Compendio heráldico arte de escudos de armas según el methodo mas arreglado del blasón, y Autores españoles, editado en Pamplona por la viuda Martin Josep de Rada en el año 1773. 


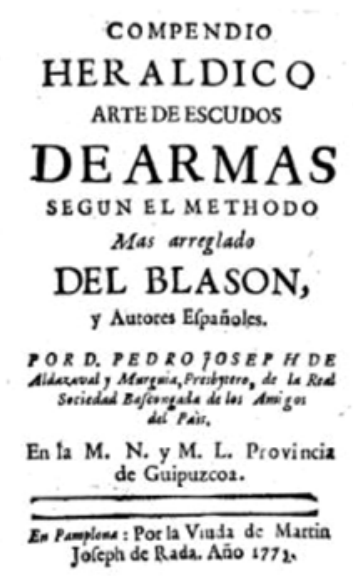

Figura 2. Libro Compendio heráldico de armas.

En ambos estudios también se hace hincapié en el hecho de vincular los blasones con el concepto del honor, siendo éste un atributo importante. Atributo que recoge en los blasones parámetros de identificación de familia, pueblo, persona, etc., además de ser, como indica Aldazaval, el testimonio de la excelencia del sujeto, de modo que estos honores queden testimoniados ante el público mediante unas señales exteriores. Y da por supuesto que estas insignias exteriores que hacen público el honor fueron, en definitiva, las que provocaron la invención del arte del blasón. Definición parecida realiza Piferrer más adelante, en la que define el blasón como "las armas e insignias, ya emblemáticas, ya puramente convencionales, con los que los nobles y caballeros de la Edad Media adornaban sus escudos para recordar algún hecho heroico, algún dato o acontecimiento notable» (Piferrer 1855).

Piferrer igualmente recoge el hecho de que los grupos que deseaban distinguirse, incluyendo en este grupo también a asociaciones y corporaciones, insertaban sus principales atributos en los blasones. Así queda fehacientemente contrastado un proceso claro de concreción de marca, dado que el blasón recogía atributos corporativos o "valores» de acciones que debían ser comunicados. De igual modo, es interesante comprobar la búsqueda de la excelencia, como sucede hoy en día, y que esta excelencia debía ser visualizada a través de signos, figuras y emblemas insertados en los blasones.

\subsection{EVOLUCIÓN DE LOS SIGNOS EN EL ARTE HERÁLDICO. El BLASÓN}

No entraremos a detallar las características específicas de los blasones o heráldicas, ya que no es objeto de este estudio. Sí que vamos, por el contrario, a incidir en las peculiaridades de la evolución de los signos y marcas que hoy en día pode- 

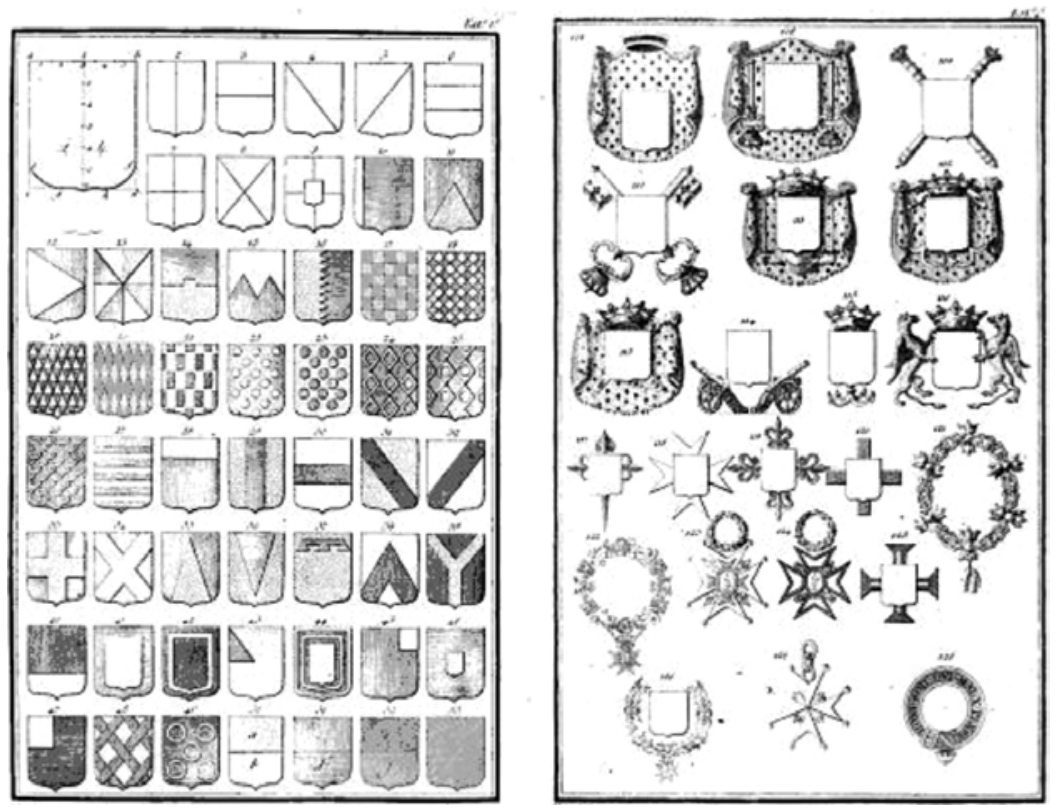

Figura 3. Construcciones y divisiones de escudos y otras figuras y símbolos.

mos discernir como tales, y que, como bien ha quedado documentado, se trata de un sistema convencional de emblemas, signos y marcas que definen la evolución de los códigos y que han ayudado a producir el sistema actual de marca e identidad corporativa.

De la evolución del arte heráldico se extraen los puntos clave que determinan un método básico convencional del blasón, teniendo en cuenta que los blasones son sistemas que codifican un conjunto complejo de signos que permiten identificar a su portador, ya que la función principal de un blasón es idéntica a la que viene codificada en el nombre.

Así vemos que:

- El nombre de los escudos se identifica y, en consecuencia, tiene «nombre» por las figuras y divisiones del mismo.

- La construcción y las divisiones de los escudos están debidamente detalladas.

- Las figuras que se incluyen poseen un nombre, proporción y significado específicos, y permiten identificar de manera más precisa al portador.

- Los colores de los metales y los colores que se usan en el blasón poseen nombres y términos específicos. Realizados con un claro carácter simbólico y asociados de manera importante a atributos que definen a su portador en relación con las acciones que debe acometer.

- La forma específica del blasón inicialmente no es relevante a nivel de significación. 
Dentro de este sistema básico de código "corporativo» encontramos nombre, color, forma y figuras, que tienen un claro fin identificativo, asociado en gran medida a unos atributos y aspectos, y que hoy serían claramente definidos como parte de la identidad corporativa.

Vemos cómo los nombres, los colores y las formas y divisiones de los escudos están perfectamente presentados y definidos en compendios y tratados (Aldazaval 1773; Piferrer 1855), por lo que se aprecia un carácter y disciplina perfectamente regulada. Para Mikhail Y. Medvedev (2012) un blasón «no es ni una fórmula ni una representación visible, y existe solamente en una conciencia debidamente culta. Al mismo tiempo, al igual que una figura geométrica, un blasón puede ser representado de forma verbal o gráfica, siendo una condicionalidad inteligible».

\subsection{El COLOR EN EL ARTE HERÁldico}

Uno de códigos más relevantes en el arte del blasón y los escudos se produce en el color. Se enfatiza tanto en el color de los materiales o metales que se incorporan a los escudos como en los colores pintados o mediante los elementos bordados en los estandartes y en los blasones. Sin embargo, vemos que los primeros en definir, simbolizar o significar los colores fueron los troyanos (Piferrer 1855), haciendo que los colores significasen los siete días de la semana (comenzando por el domingo): oro quinagi, plata senato, encarnado fruti, azul detradi, negro parafreci, verde estela, púrpura pesati. Ya en época de Aristóteles, éste hace coincidir los colores con los planetas haciendo llamar al oro, Sol; a la plata, Luna, al encarnado, Marte; al azul, Júpiter; al negro, Saturno; al verde, Venus; y al púrpura, Mercurio. Igualmente se identificaba, se vestía, se pintaba o se asociaba el color o el metal correspondiente a cada uno de los dioses. Más adelante, llaman a los colores con los nombres de las virtudes teologales y cardinales. Así el oro es fe; la plata, esperanza; el encarnado, caridad; el azul, justicia; el verde, fortaleza; el negro, prudencia; y el púrpura, templanza. Ya los antiguos heraldos de armas nombraron los colores (también colores de los metales nobles) que aparecen en los blasones del modo siguiente: al color amarillo lo llamaron oro, al blanco, plata; al verde, sinople; al negro, sable; y al violado, púrpura.

Aldazaval, por su parte, incorpora un mayor número de colores, en los que observamos cómo se suman los significados dados en épocas pretéritas como elementos simbólicos $(1773,26)$. Así, además de especificar los colores anteriores, les incorpora cualidades significantes (por ejemplo, el negro denota dolor). De igual modo, para una mejor comprensión y concreción de lo que expresa el color se convencionalizó su representación mediante un código estricto de dibujo de líneas y puntos creado por el padre Silvestre de Petra Santa, que, como se indica, «inventó el modo de significar en cifra los dos metales (el oro y la plata) y los cinco colores» (figura 4).

De tal modo que los puntos pequeños en un dibujo significasen el oro (color amarillo); la plata (color blanco), liso; el sable (color negro) se definía mediante líneas que se cruzan entre sí horizontal y perpendicularmente; el púrpura (también identificado como morado) se significaba mediante líneas desde el ángulo izquierdo 


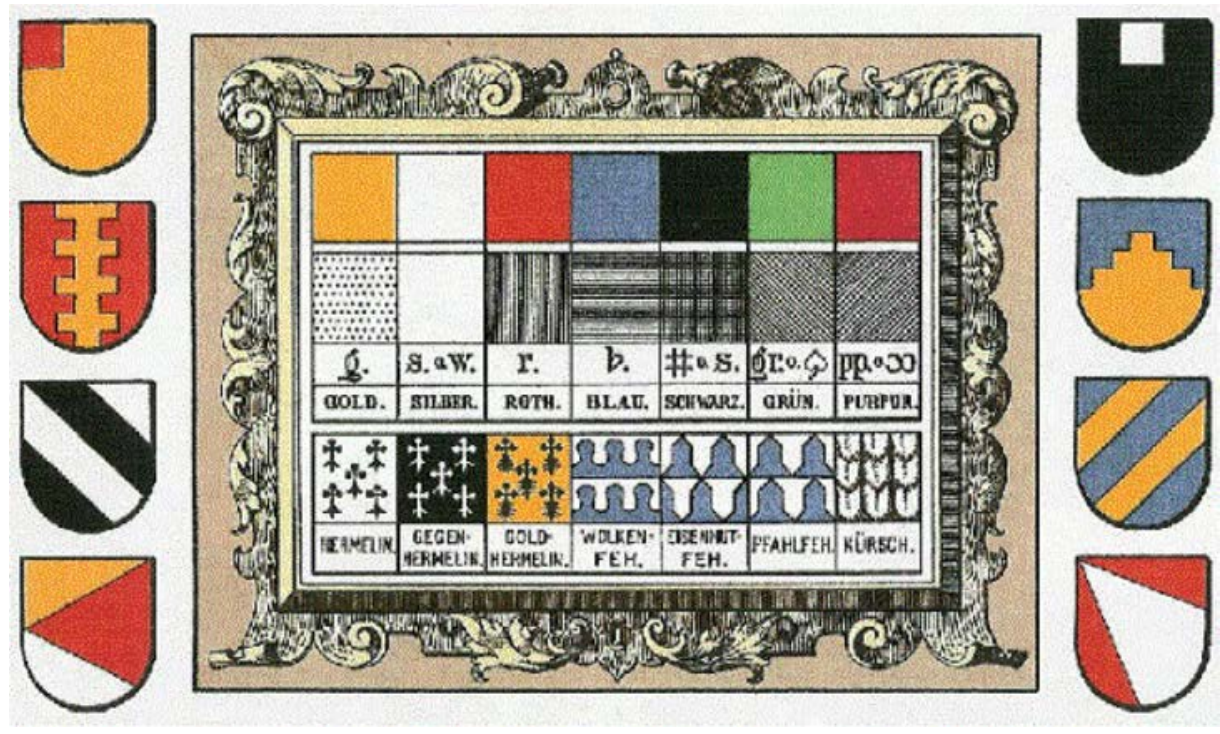

Figura 4. Código estricto de dibujo de líneas y puntos, creado por el padre Silvestre de Petra Santa para representar los colores.

superior del escudo hasta la parte derecha inferior en diagonales; el sinople (color verde) se definía mediante líneas en diagonal desde el ángulo derecho superior del escudo hasta la parte izquierda; el azur (color azul), mediante líneas horizontales; el gules (color rojo), mediante la representación de líneas trazadas perpendicularmente. Vemos, pues, una nomenclatura básica del color mediante un uso deliberado de formas básicas: líneas y puntos. Digamos, por último, que los colores con el tiempo se vieron ampliados a unos cuantos más.

A esto se ańade una fuerte carga simbólica incorporada al color, asociada a los nombres pretéritos dados y vinculados a planetas y virtudes, entre otros. Con la consecuente asociación de atributos simbólicos de carácter religioso, astronómicoastrológico. Así, por ejemplo, el metal oro (y color amarillo) simboliza el blasón de los planetas de Sol, entre los signos celestes se asocia al León, entre los elementos se vincula al fuego, como día de la semana es el domingo, de los meses del año es julio, en relación con las piedras preciosas es el carbunclo, de las virtudes representa la caridad, de las cualidades mundanas representa la magnanimidad, la riqueza, el poder, el esplendor y la prosperidad.

De todo esto se deduce que además de normalizar gráfica y cromáticamente su representación existe una evolución de cualidades como signo cultural que se van incrementando y enriqueciendo a lo largo de siglos. En este contexto resulta evidente lo que más adelante detallaremos; esto es, que, como indica Eco $(1988,172)$, para que haya código resulta imprescindible que exista una correspondencia convencionalizada y socializada. Del mismo modo afirma que «hay comunicación difícil, 
no cuando no hay signos reconocidos como tales, sino precisamente cuando los signos son reconocidos, y a pesar de ello los códigos son defectuosos». Lo que hace que, desde la perspectiva de la semiótica social, el signo sea signo por la institución de una función significativa previamente establecida por una comunidad. Por lo tanto, además de ser una convención socialmente instituida, esta convención varía en cada cultura y como vemos puede variar en cada época. Esto se produce en el caso del nombre dado al color, así como a sus significados denotados y simbólicos.

\subsection{SignificaCión DE LOS EMblemas HeRÁldicos}

Desde un análisis semiótico podemos estudiar con claridad la significación de los emblemas heráldicos como signos, analizándolos desde las tres dimensiones definidas por Charles Morris, y que han sido plenamente aceptadas en el mundo científico. Para Alberto Montaner: «El diasistema emblemático es el constituido por los diferentes sistemas de signos gráficos o icónicos que, más allá de sus diferencias formales, tienen en común el desempeño de la función emblemática, que es su modo de significación» $(1988,172)$. Lo que ratifica lo anteriormente desarrollado y nos permite desglosar desde un análisis semiótico más actual la significación de los emblemas.

Así, nos dice que el emblema posee un:

- Significado identificador o denotativo: ya que un emblema es un signo que contiene la imagen o noción de una persona, sea ésta física, jurídica, singular o colectiva. Por lo tanto, vincula el significante visual con el significadoidentificador. Describe, pues, al portador a través de dos planos:

- Plano del sentido: informa en abstracto de la existencia de un titular y de determinadas características de éste, a través del vínculo concreto de titularidad.

- Plano del contenido: identifica a un titular específico, a partir del conocimiento de determinadas propiedades del portador (importantes, sobre todo, desde el punto de vista de su personalidad social).

- Significado evocador o connotativo: ya que en muchos casos el elemento gráfico del emblema, el tipo de titularidad que representa u otros factores (diacrónicos, diatópicos o diastráticos) están asociados a un simbolismo que despierta diferentes sugerencias.

- Convencionalidad del emblema: ya que nace de una convención social que se ha adoptado previamente. El vínculo debe reconocerse en el proceso comunicativo y se mantiene fuera de un acto comunicativo. Por último, la función emblemática puede ser denominativa, identificadora o predicativa. 

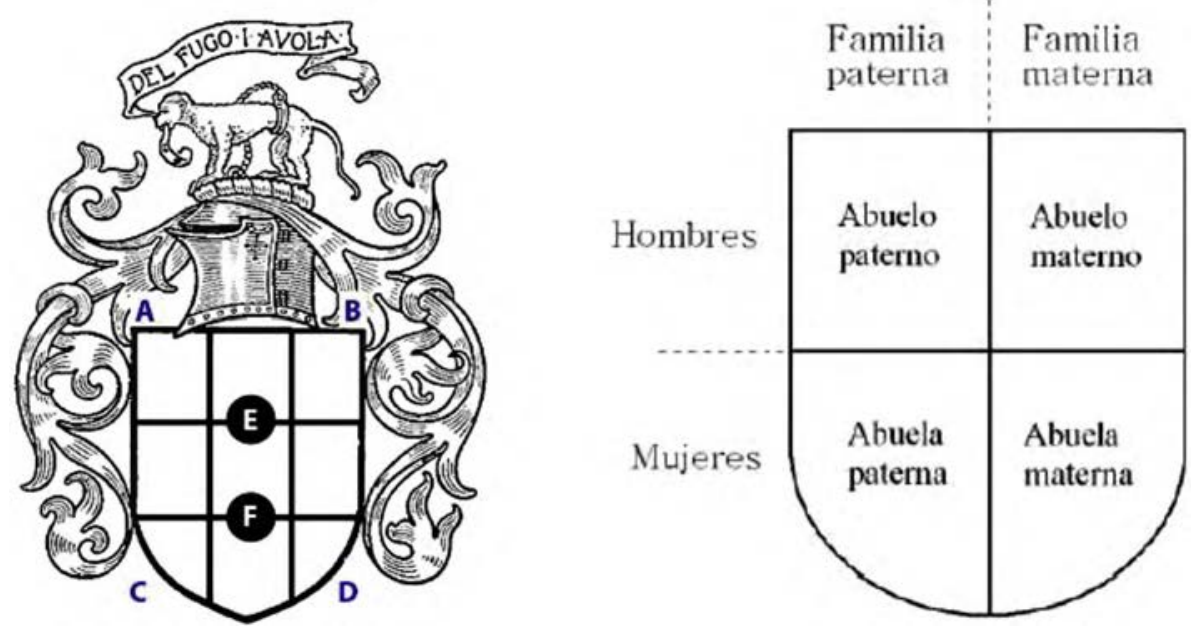

Figura 5. A la izquierda zonas y partes de un escudo y a la derecha un escudo partido. Nace en la heráldica espańola y sirve para representar las armas de ambos cónyuges o de los padres de una persona.

\section{LAS CORPORACIONES Y OTROS GRUPOS DE PODER QUE HACEN USO DEL ARTE HERÁLDICO}

El paso de una sociedad feudal regida por una economía agraria y rural a una progresiva aparición de gremios y cuerpos de oficios especializados marcó el desarrollo de un sistema corporativo medieval (Costa 2004). De hecho, aunque habitualmente se relaciona el arte heráldico con los escudos de armas de la antigua nobleza feudal, éste pasó a desarrollarse en todo tipo de asociaciones y corporaciones en su evolución de una economía feudal a una economía artesanal. Esto hizo que proliferasen todo tipo de insignias y blasones en los gremios y asociaciones de todas clases, como da cuenta Francisco Piferrer $(1855,7)$. Es justamente en este grupo gremial, que desarrolla oficios específicos, donde se acuña por primera vez el concepto corporativo que deviene de la palabra latina corpus.

Este proceso abarcó igualmente a grupos civiles, religiosos y, cómo no, militares, siendo la marca nacional la más reciente (Montaner 2012). Cada uno con sus peculiaridades, marcaban una metodología específica en función del grupo al que pertenecían. Así, por ejemplo, los grupos religiosos optan por el uso de insignias en las que incorporan elementos y símbolos propios del clero. Encontramos cómo la tiara y las llaves son el símbolo o «marca» del pontífice, los cardenales timbran sus escudos con un sombrero encarnado y los arzobispos con un sombrero forrado de verde, entre otros. Ciertamente este grupo consta de innumerables jeroglíficos o símbolos incorporados en sus insignias y timbres, que definen cada uno de los grupos que lo constituyen, formalizando, no solamente, una primitiva identidad cor- 


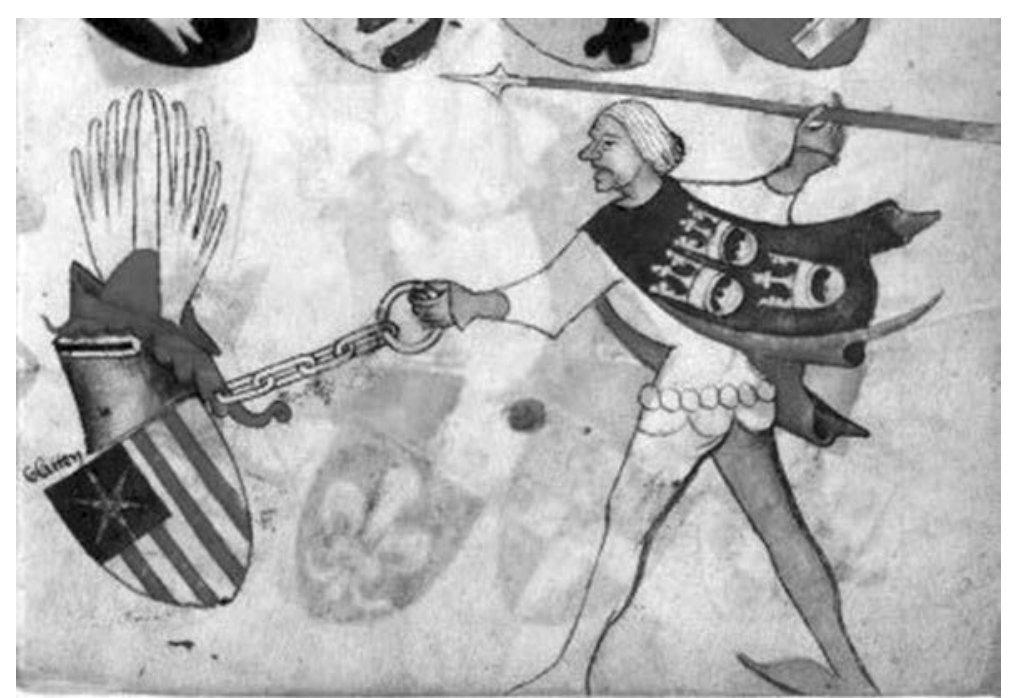

Figura 6. Heraldo de armas representado en el Armorial Bellenville con las ya asumidas armas de oficio, ubicadas en la capa (las tres coronas).

Extraído de la ilustración en BN París, ms. Fr. 5230, fol. 70r.

porativa compleja, que se identifica también por las características de la indumentaria del grupo.

En esta época los símbolos, que concentran y definen un grupo específico, disponen de una gran carga simbólica y recogen un gran número de significados (Aldazaval y Murguía 1773). De igual modo vemos que las normas y jerarquías se concretan no solamente en los blasones (que incluyen varios elementos como el timbre, lema, tenantes, etc.), sino en la indumentaria, banderas, escudos o armaduras que definen un carácter identitario (Eco 2009). De hecho, el proceso de concreción del uniforme militar del siglo XviII deriva del proceso evolutivo de los signos de reconocimiento anteriormente mencionados, como emblemas o estandartes, entre otros.

Hay que destacar que dentro del sistema emblemático este quinto repertorio de elementos «ornamentales» en el blasón comienza a tener su auge a partir del siglo XIV (Montaner 2012) y, como vemos, son los que permiten identificar grupos y categorías de grupos.

Generalmente estos elementos se sitúan junto al escudo y están englobados del siguiente modo:

- El timbre, que incluye como forma básica corona y yelmo, que puede estar con o sin cimera.

- Tenantes, también llamados soportes.

- Collares, cintas y cordones, que rodean, o mantos y pabellones englobándolos.

- Lema o divisa, que identifica al portador. 


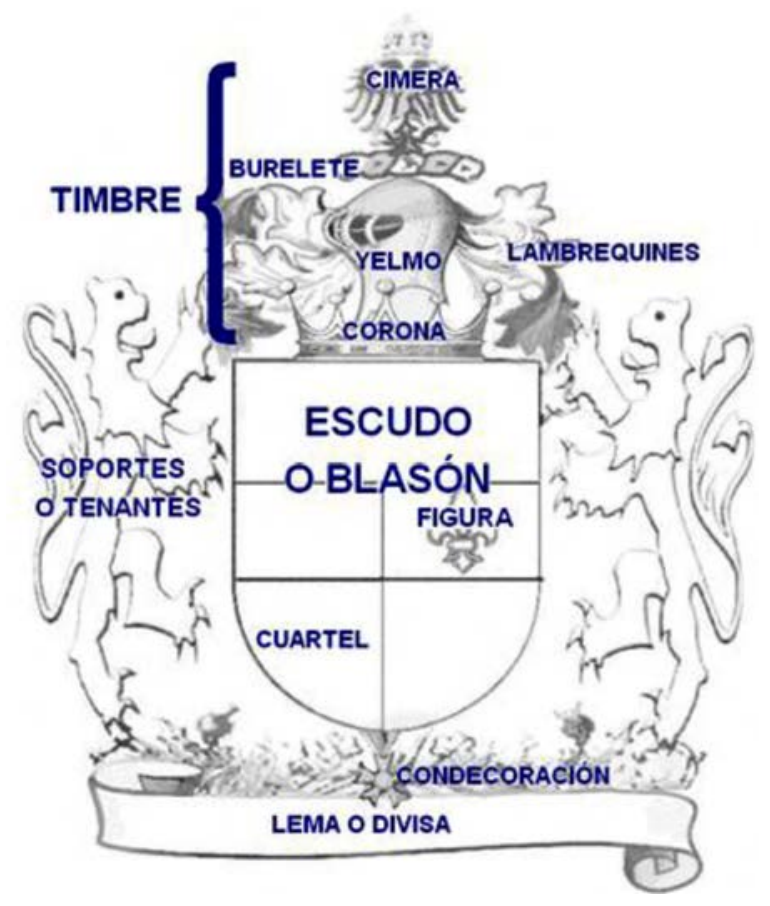

Figura 7. Estos elementos ornamentales permiten diferenciar, por ejemplo, las distintas cancillerías, cargos, etc.

Así se aprecia que estos elementos «ornamentales» ayudan a diferenciar niveles jerárquicos dentro de la iglesia y las monarquías con variantes de color, o variantes en el timbre o divisa, que permiten identificar de manera más precisa al portador.

\section{CONTEXTO DEL SURGIMIENTO DE LA HERÁLDICA PROFESIONAL}

Ya hemos visto cómo se va generalizando el uso del sistema heráldico en diferentes grupos de poder. Para comprender de una manera más precisa la heráldica profesional haremos un inciso histórico que nos permita comprender de un modo más amplio el segundo nacimiento de la marca comercial.

Es a partir del Alto Medievo, entre los siglos XI y XII, cuando se produce en toda Europa un resurgimiento económico y una mejora en las comunicaciones, favorecida por las rutas marítimas, que impulsan también el comercio entre Oriente y Occidente. Al tiempo, se produce un aumento de la población, gran parte de la cual se traslada a las nuevas urbes, recuperando la actividad comercial y urbana. Un hecho que no se producía desde la caída del Imperio romano y que está propiciado 
por la conclusión de guerras por parte de los escandinavos en el mar del Norte, los cuales se focalizan en una actividad comercial. Esto provoca el florecimiento de los Países Bajos, la expansión comercial entre Francia e Inglaterra, así como las cruzadas. Esta última es, entre otras, una de las actividades que impulsan la reactivación comercial marítima en el Mediterráneo, favorecida por la reapertura al comercio con la intervención de Génova, que pasa a ocupar Córcega, Sicilia y Cerdeña (Henri Pirenne [1933] 1975).

Este hecho hace que la antigua cité y el burgo $0^{4}$ pasen a constituir las ciudades medievales, favorecidas por el renacimiento comercial que se inicia en el siglo $\mathrm{X}$ y que se consolida en el siglo xI. En esta ciudad medieval se afianza la nueva economía y se produce la llamada "revolución comercial», en la que las actividades productivas se refuerzan en agrupaciones mercantiles dotadas de personalidad jurídica, las cuales disponían de un espacio físico donde realizar su actividad comercial (Martínez Llorente 2012). En este nuevo enclave es donde los individuos de esta nueva "clase», que vive del intercambio comercial y la industria, comienzan a ser denominados burgueses. Los mercaderes y artesanos se agrupan por barrios, colonias o burgos comerciales. Con el tiempo pasan a disponer de cierta autonomía, inicialmente ilegal, para organizar sus asuntos y comienzan a promulgar constituciones urbanas que dotan a las ciudades y a los ciudadanos de derechos especiales 5 .

\subsection{LA HERÁLDICA PROFESIONAL: LOS GUILDES}

Las nuevas clases de profesionales de toda índole, que se generan en las nuevas ciudades medievales, acabarán agrupadas en gremios o guildes. Los nuevos grupos corporativos gremiales, cofradías, compañías y hansas irán adoptando el sistema emblemático creando nuevos símbolos que acabarán conformando la heráldica corporativa o profesional. Para Joan Costa (2004) la incorporación de los escudos en los oficios corporativos fue un uso obligado con el fin de poder identificar claramente al portador, ya que tenía una función fiscalizadora, por lo que debían estar perfectamente clasificados. Este hecho queda testificado por Javier Alvarado, quien identifica el papel de control de las asociaciones profesionales, las cuales ejercen de órga-

${ }^{4}$ Henri Pirenne (1975) en su Historia económica y social de la Edad Media explica la evolución que sufren estos dos núcleos de población de origen distinto. Las cités (traducido al español como villes) son en sus inicios ciudades que tiene su origen en el Imperio romano y gozan de una organización municipal propia del Imperio. Éstas en el mundo cristiano comienzan a ser identificadas como sedes episcopales organizadas en torno a una catedral y estaban habitadas por estamentos religiosos, con un comercio rudimentario. Como máximo podían llegar a tener 3000 habitantes. El burgo, por su parte, surge como consecuencia de la fragmentación del Imperio carolingio. En su origen es una fortaleza dispuesta para defender territorios en litigio, gobernada por un alcalde (asignado por el señor feudal) y habitada por un destacamento militar. Como máximo podía llegar a tener 1000 habitantes.

5 Henri Pirenne (1975) indica que en siglo XII comienzan a promulgarse en los burgos de Flandes (Brujas, Gante) constituciones urbanas que contemplan varios derechos, entre ellos la capacidad de los burgueses para solucionar las querellas relativas a sus negocios. 


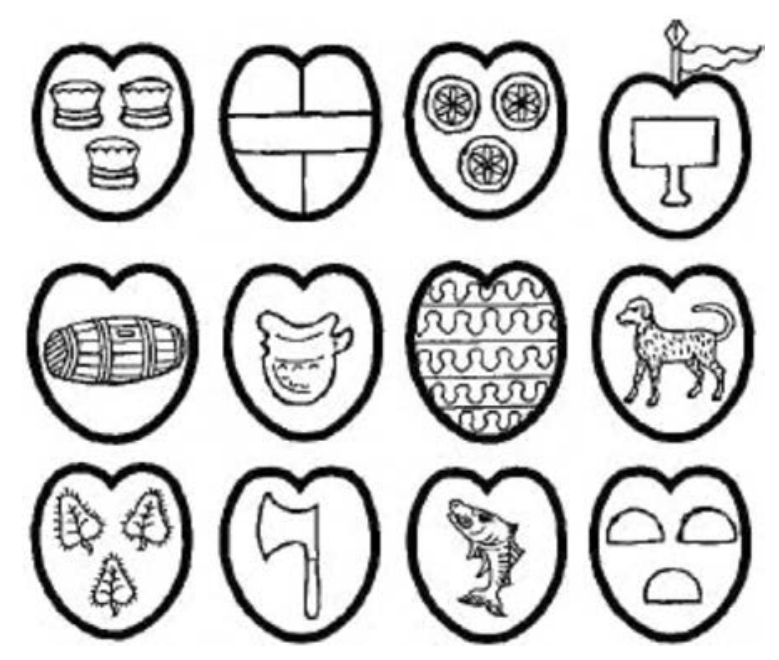

Figura 8. Escudos del siglo XIV pertenecientes a artesanos y campesinos del condado de Clemont-en-Beauvaisis.

nos de recaudación fiscal de sus asociados $(2009,27)$. Indicando al mismo tiempo que éste fue uno de los factores que influyeron en el apoyo de las monarquías a los movimientos corporativos. Igualmente se fijaron plazas fijas para cada uno de los gremios delimitando por zonas su labor profesional, en función de la labor desarrollada en sus gremios.

Otro aspecto importante es el hecho de que, desde los comienzos del Medievo, tanto artesanos como campesinos tenían derecho a llevar armas. Esto es así porque cualquier persona libre podía diseñar su emblema heráldico (Alvarado 2009). Así vemos que la aparición del arte heráldico profesional está asociada a la libertad y el derecho a la propiedad (Costa 2004). De igual modo, se observa que los escudos de estos grupos sociales son en los primeros tiempos más sencillos, aunque poseen un repertorio mayor.

Todos estos nuevos mercaderes y artesanos agrupados en colonias o burgos generan una heráldica que permite identificar a un maestro específico y más concretamente al grupo gremial o a asociaciones gremiales. La evolución que toma la generación de un imaginario iconográfico no acaba identificando a un gremio por su actividad profesional, sino que identifica a una nueva personalidad jurídica o corporativa ${ }^{6}$ que viene definida por la constante repetición de los signos y símbolos, definiendo de este modo una identidad corporativa.

${ }^{6}$ Félix Martínez Llorente (2012) define del siguiente modo la heráldica profesional: «Aquella desarrollada por y entre aquellas gentes que a la hora de la confección o definición de sus emblemas personales -haciendo salvedad en este momento a que se haga heráldicamente o no- se decantan 

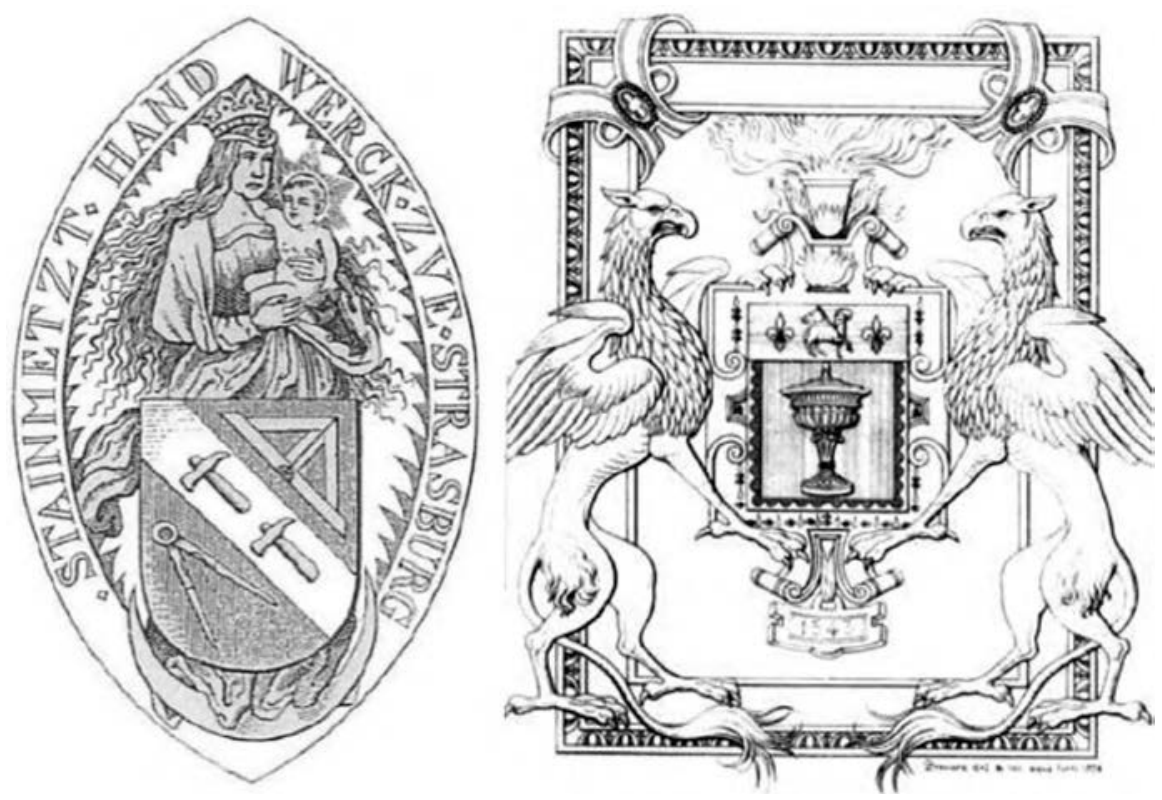

Figura 9. Izquierda: emblema oficial de la Bauhütte o de la federación de todos los talleres de arquitectos y talladores de piedra de Santo Imperio Germánico s. XvirI. El escudo de la corporación aparece debajo de la advocación de la Virgen. Derecha: armería del gremio de orfebres de la villa de Rouen (Francia, 1543), que estaba reproducida en la vidriera que se hallaba en su sede corporativa (trasladada al Musée des Antiquités de la Seine-Maritime de Rouen).

Hay que señalar que el proceso es irregular en toda Europa. Encontramos que las autoridades exigen un mayor control y conocimiento de los emblemas corporativos que eran empleados en sus sociedades con la finalidad de vigilar el producto final: derecho a la marca, apoyo al prestigio, autoría y crédito industrial. Así, vemos que todos los artesanos deben declarar su marca tanto a las corporaciones

por la adopción de emblemas o signos que de manera expresa o meramente instrumental, guardan estrecha relación con el objeto último de su actividad u oficio». También incide en el hecho de que «una progresiva y constante repetición de formas y fórmulas emblemáticas por un determinado colectivo profesional llegará a proporcionar, con el tiempo, un conjunto de signos de identidad corporativos que debidamente organizados o iconográficamente definidos, llegarán a convertirse, en el seno de las agrupaciones gremiales en las que se llegan a vertebrar y tomar cuerpo los diferentes oficios o actividades económico-profesionales, en novedosa emblemática corporativa que identificativa de una nueva personalidad -la jurídica o corporativa- vendrá a representar por igual a todos y de la que todos serán beneficiarios». 


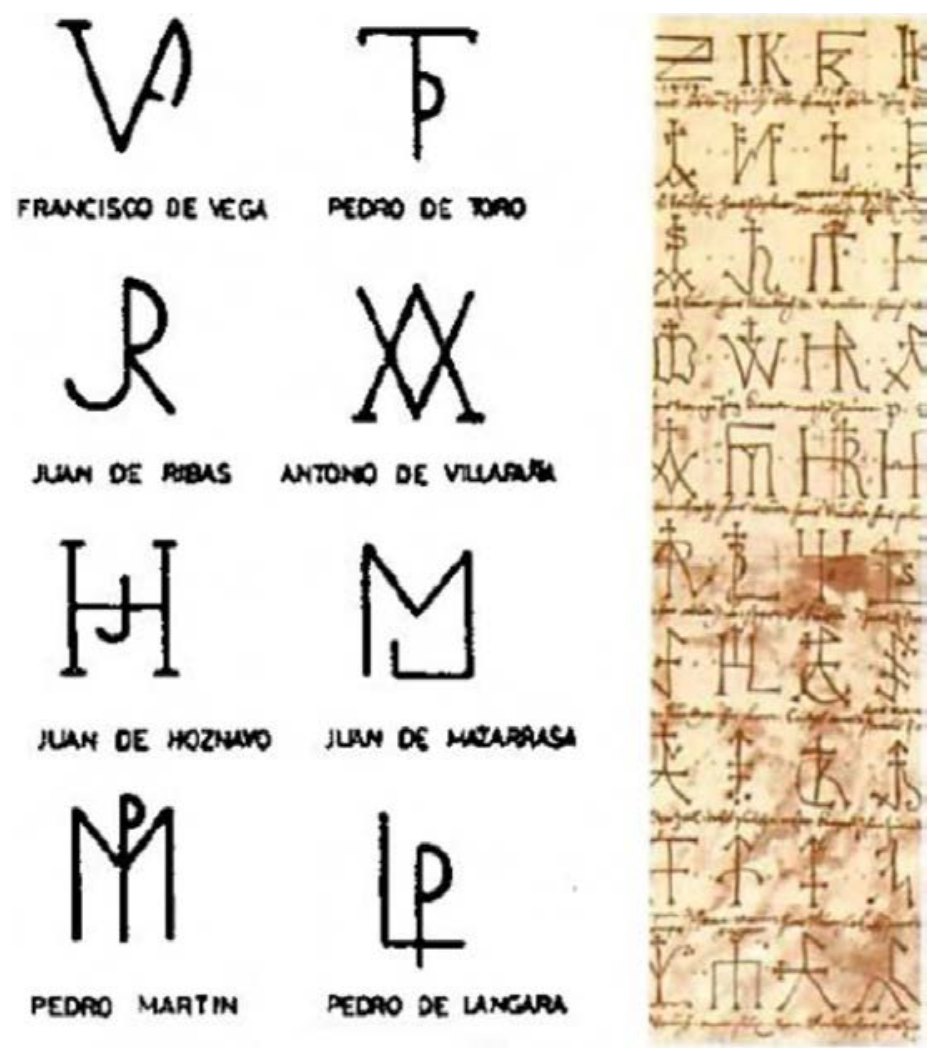

Figura 10. Izquierda: marcas onomásticas de maestros canteros del siglo Xvi. Por lo general las marcas de los maestros canteros hacían referencia a un instrumento de la construcción: escuadra, regla, compás, maza, etc. Pero se encuentran casos de marcas personales onomásticas, como es el caso del ejemplo de la figura 18. Derecha: registro de marcas de mercaderes (1495-1527). Extraído del manuscrito 2908, fol. 1 v , que se encuentra en la Biblioteca del Germanisches Nationalmuseusm de Nuremberg.

como a las autoridades en un registro público, como ya hemos indicado anteriormente. En muchos casos, la marca personal del oficial o artesano (signum artificis) debía ir acompañada de la marca de la corporación o del taller (marchum artis). La marca personal no podía venderse ni cederse, y servía igualmente para evitar falsificaciones (Alvarado 2009).

Aunque en lo que se refiere al diseño de las armas este control es escaso en muchos países, sí se encuentran evidencias importantes en la Casa Real británica de tener adjudicada la última decisión sobre la elaboración, rehabilitación y mejora de todos los escudos de armas (tanto para personas físicas como jurídicas) en uso de Gran Bretańa. Diseño que era llevado a cabo por un heraldista colegiado del reino. 


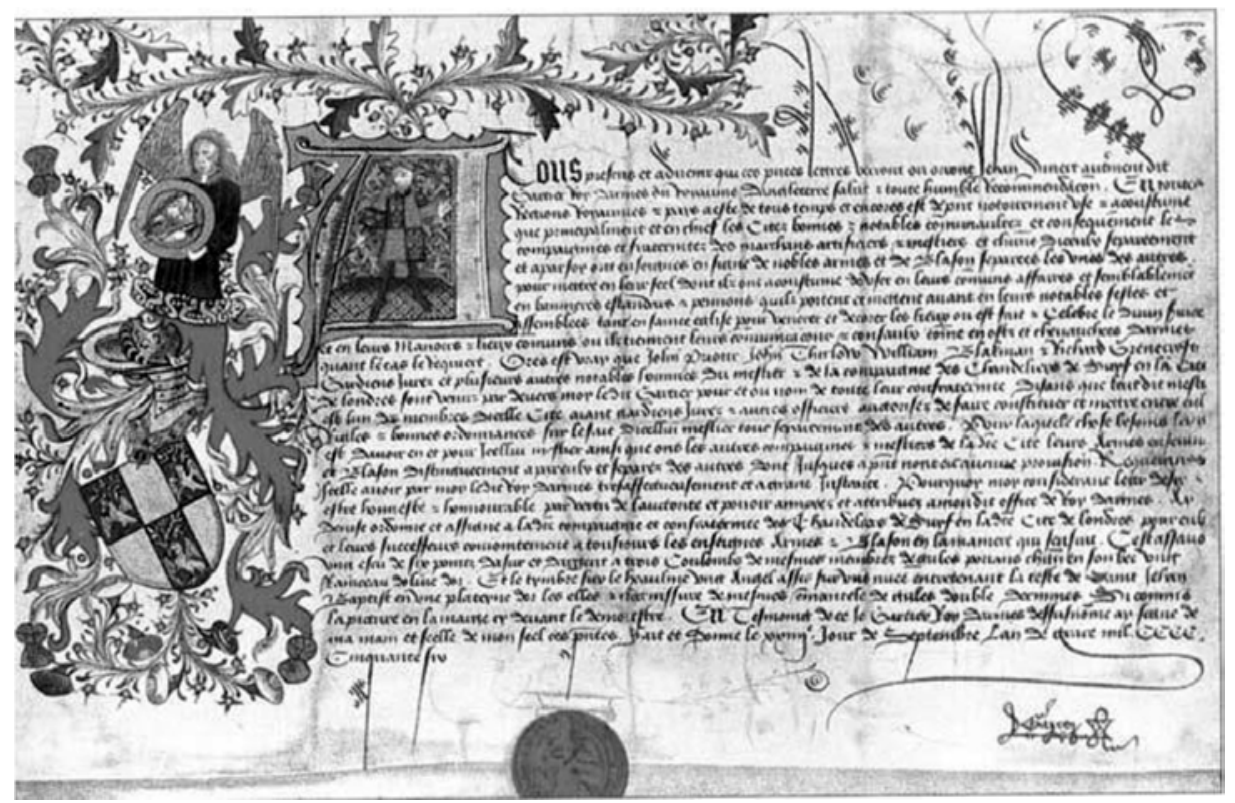

Figura 11. Certificación de armas del gremio de fabricantes de velas de sebo de la ciudad de Londres, expedido el 24 de septiembre de 1454 (bajo el reinado de Enrique IV,

1422-1461), en el que se indican las características del blasonado (Martínez Llorente 2012).

Se aprecia el rigor en la elaboración, la profesionalidad en la creación de los blasones mediante una certificación y el «diseño» realizado por un colegiado profesional.

\subsection{LA HERÁlDICA PROFESIONAL: MATRIZ GEOMÉTRICA PARA EL DISEÑO DE MAR- CAS DE CANTERÍA}

Hemos visto cómo para la creación de escudos se requería de un proceso específico de divisiones que definían su significado y que estaban debidamente detalladas. En el caso específico de los gremios canteros, el diseño de sus marcas de cantería es muy extenso y viene determinado por función y autoría llegando a dilucidar signos o graffitis realizados por religiosos, viajeros e incluso prisioneros. Para ver la complejidad existente y concretar posteriormente las marcas, adjuntamos el esquema definido por Jean-Louis Van Belle, en el cual se detalla la jerarquía de signos que se pueden encontrar en los edificios (Van Belle 2001). En nuestro caso, nos centramos en las marcas de compañero y más específicamente en las identitarias (de identidad), compuestas a su vez por las individuales (marcas de cantero) y las colectivas (sellos corporativos de los gremios o talleres), que son los signos grabados en la piedra de las edificaciones y que por otros estudiosos, como Alvarado, son definidos como marcas personales del oficial o artesano (signum artificis) o marcas de las corporaciones o del taller (marchum artis), como anteriormente ya hemos indicado, extensibles a todos los gremios. 


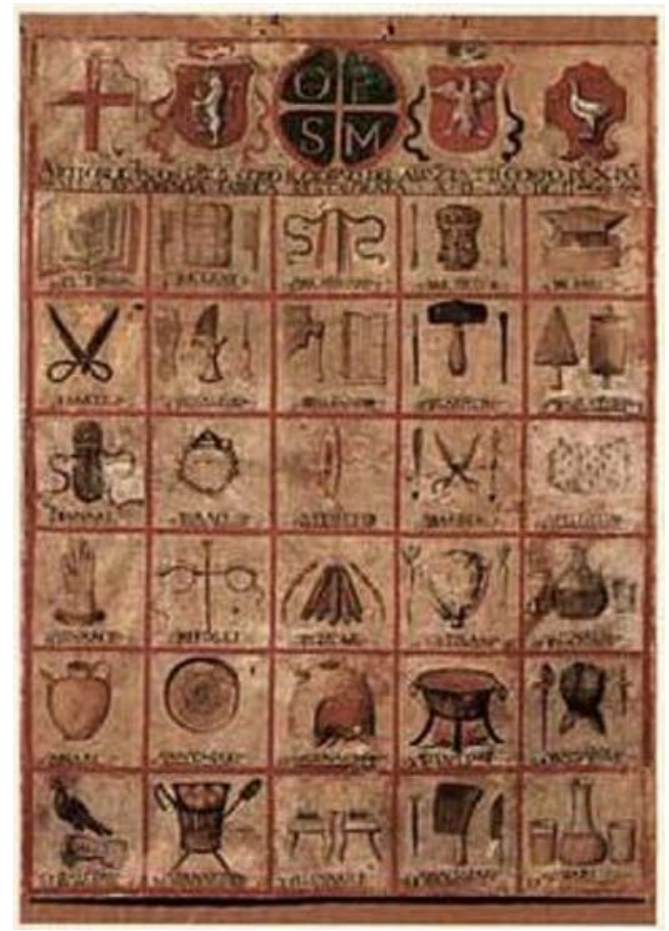

Figura 12. Marcas de las corporaciones de Orvieto (ańo 1602), donde se definen cómo son cada una de las marcas para cada una de las corporaciones.

En el caso de las marcas heráldicas de los canteros, sus marcas individuales y colectivas, o marcas personales del oficial o artesano y marcas de las corporaciones o del taller, se rigen por un diseño específico basado en tramas geométricas. Sin embargo, el origen del uso de tramas geométricas se sitúa ya en el arte bizantino y existen recopilaciones de más de 9000 marcas de cantería y de honor del periodo gótico, románico y bizantino, como la realizada por el arquitecto vienés Franz Rziha (1993). Tras analizar las marcas de las corporaciones de talladores y arquitectos de la Bauhütte, Rziha observó que todos los signos estaban basados en un orden geométrico que se obtenía mediante el uso de escuadra y compás. Para Javier Alvarado estas corporaciones suponen la continuidad de la tradición constructiva romana $(2009,54)$. Al igual que Rziha, que fue capaz de documentar marcas romanas en edificios tan emblemáticos como el Capitolio, Pompeya o el Palacio Diocleciano en Spalato.

Los estudios de Rafael Fuster y Jordi Aguadé (2017) muestran y reafirman la relación entre la ingeniería aplicada en la construcción arquitectónica de los arcos, plantas, etc., y las retículas constructivas de las marcas de honor, marcas de maestro o corporativas. Todo ello tras analizar el trabajo, entre otros, del 


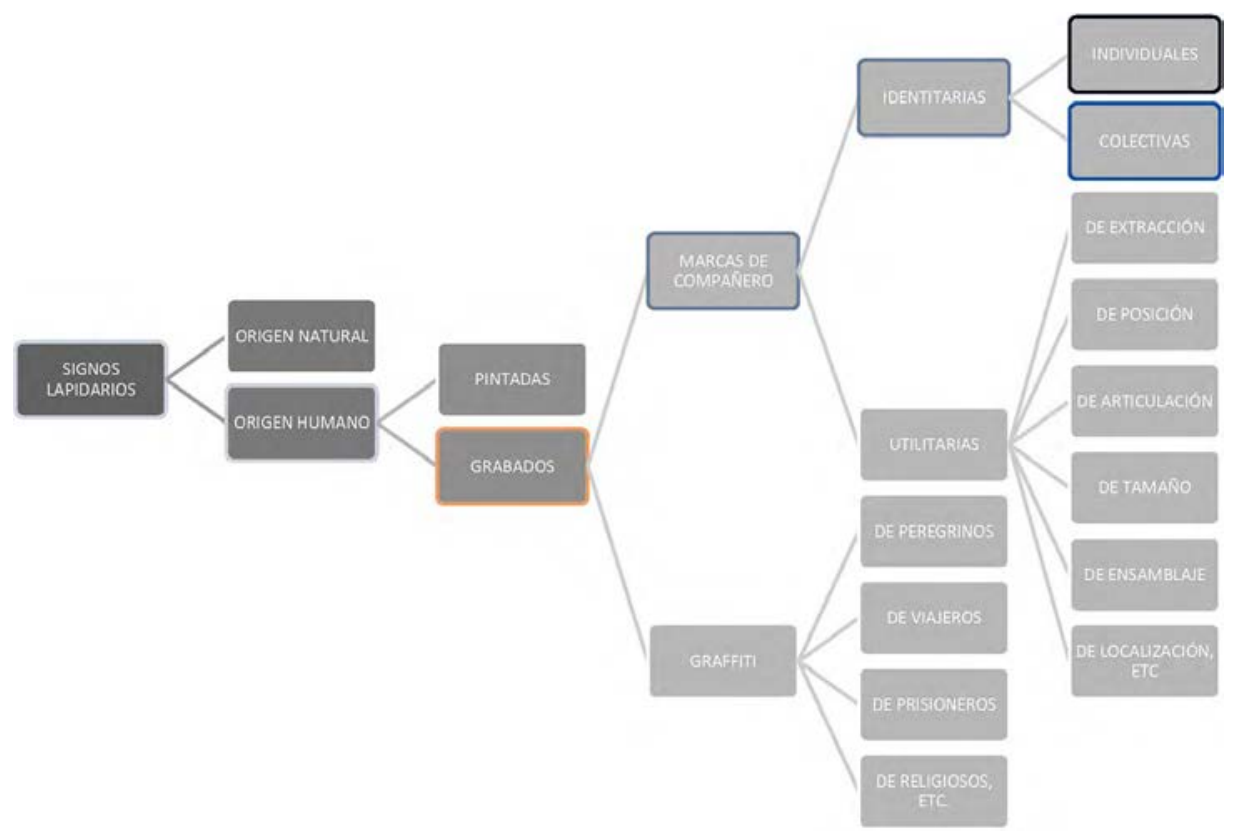

Figura 13. Clasificación de los signos lapidarios en relación con su autoría y función, definida por Jean-Louis Van Belle. Hay que indicar que las marcas identitarias no se encuentran únicamente labradas en la piedra de las edificaciones, sino que las encontramos en otros soportes.

arquitecto Rziha. Éste determinó el uso de cuatro tramas geométricas básicas: ad cuadratum, ad triangulum, cuadrilobular y trilobular (figura 15). Así pudo ilustrar cómo los diseños de las marcas estaban relacionados con las geometrías definidas en el diseño de estas plantillas. Igualmente se detalla cómo estas redes están asentadas en la herencia de una tradición arquitectónica que se traslada a fundamentos geométricos pitagóricos, donde las leyes de la proporción son el vehículo de expresión empleado por los maestros.

Las cuatro matrices tipo definidas por Rziha y detalladas por Alvarado son las siguientes:

- Ad cuadratum: está basada en un sistema de particiones de ortogonales y oblicuas que se obtienen de la superposición de dos cuadrados variando el ángulo en 45 grados en uno de ellos. Este proceso se repite y se crea una red matricial. Esta matriz era de uso exclusivo para los gremios que dependían de la Gran Logia de Colonia.

- Ad triangulum: está definida por una red triangular de triángulos equiláteros superpuestos y que conforman un hexagrama. Como en el caso anterior, estaba restringido su uso a los gremios de la Gran Logia de Colonia. 


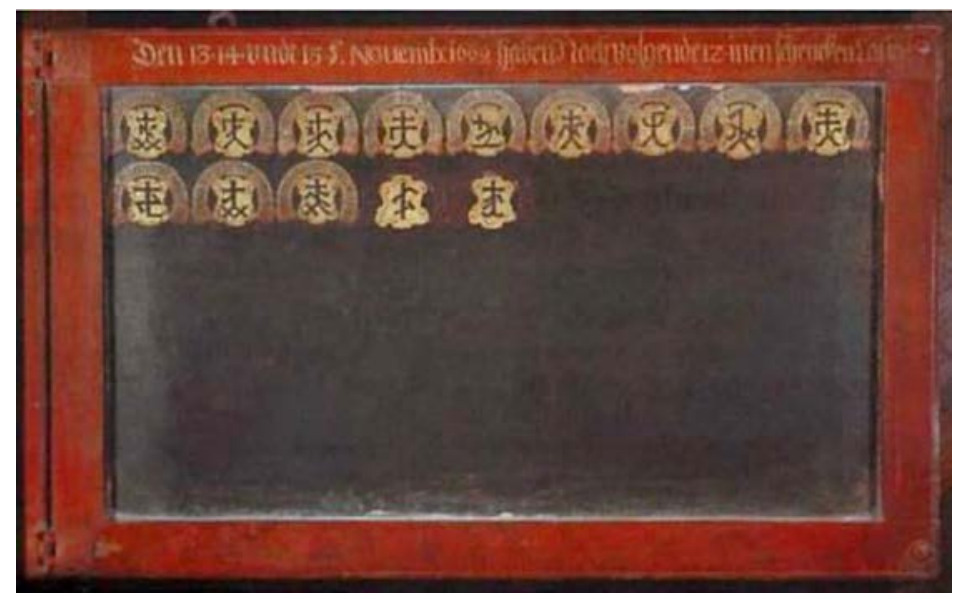

Figura 14. Escudos, con la marca en su interior, de catorce maestros de obras de la catedral de Estrasburgo, 1669.
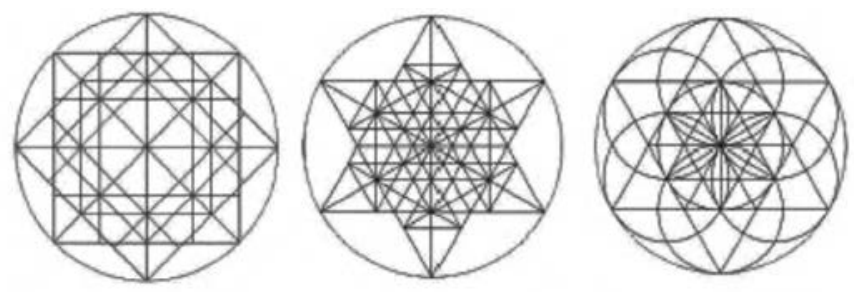

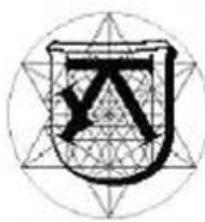

Heses KnMaxilia

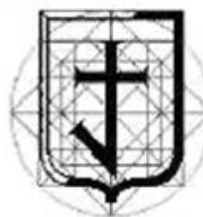

Coened flowiuar 1 4\%

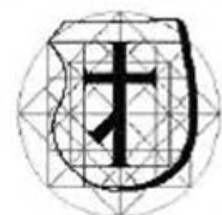

Mothine koriven Gikde Coeral Malite i Rubideria?
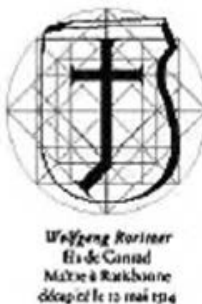

Figura 15. Superior: Franz Rziha, tramas geométricas básicas: cuadrada, triangular y circular, que sirven de base para el diseño de las marcas personales y de las corporaciones. Inferior: algunas marcas de las corporaciones de talladores y arquitectos de la Bauhütte.

- Cuadrilobular: se genera partiendo de la red cuadrangular, en la que se trazan círculos circunscritos. Los signos que se obtenían de esta matriz eran de uso exclusivo para los gremios asociados a la Gran Logia de Viena. 

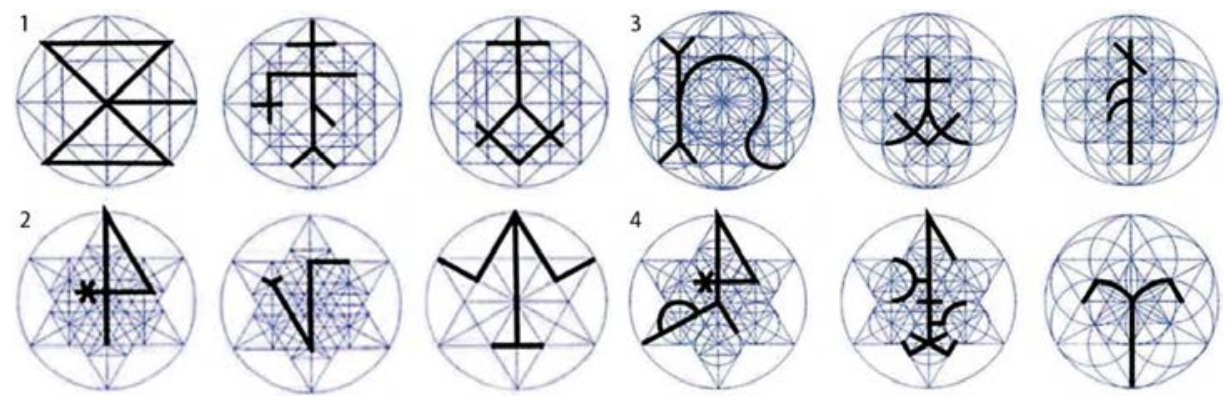

Figura 16. Doce ejemplos de marcas de canteros basadas en las cuatro tramas geométricas básicas: ad cuadratum (grupo 1), se encuentran en la catedral de San Esteban de Viena, catedral de Ulm y la iglesia de Santa Bárbara de Kuttenberg, en Bohemia. Ad triangulum (grupo 2), podemos ver las marcas en la catedral de San Guy, en Praga, la iglesia de San Jacob, en Brünn, y la iglesia de San Pedro de Laun, en Bohemia. Cuadrilobular (grupo 2), se encuentran en la catedral de San Esteban, en Viena, en la catedral de San Guy de Praga y en la iglesia de Santa Bárbara de Guttenberg, en Bohemia. Y trilobular (grupo 4), las marcas se encuentran en la catedral de San Guy de Praga, en la iglesia de Santa Bárbara de Guttenberg, en Bohemia, y en la catedral de Ratisbona.

- Trilobular: se obtiene partiendo de la red triangular en la que se trazan círculos circunscritos. Las marcas lapidarias generadas con esta red geométrica estaban restringidas para el uso de gremios asociados a la Gran Logia de Berna y la Gran Logia de Bohemia.

Se aprecia la evolución constructiva basada en una red geométrica fundamental (Steinmetzgrund) que bebe de fuentes occidentales y evoluciona en la medida en que se amplían las bases constructivas de los gremios de arquitectos y canteros. Constatando un uso más o menos estandarizado para la creación de marcas basado, en este caso, en la trama reticular base para su diseño.

\subsection{VARIANTES EN EL DiSEÑo DE MARCAS EN LA HERÁldiCA PROFESIONAL MEDIEVAL}

Como sucede en la actualidad, la creación de una marca puede derivar de conceptos simbólicos, descriptivos, etc. En el caso de las marcas en la heráldica profesional podemos discernir unas variantes específicas que pasamos a detallar del siguiente modo:

- Marcas identificativas o representativas: basadas en formas que describen con claridad la actividad del gremio o del comerciante mediante el uso de herramientas propias del oficio (figura 17).

- Marcas onomásticas: basadas en las siglas del nombre personal. Son más comunes como marcas personales (figura 10). 

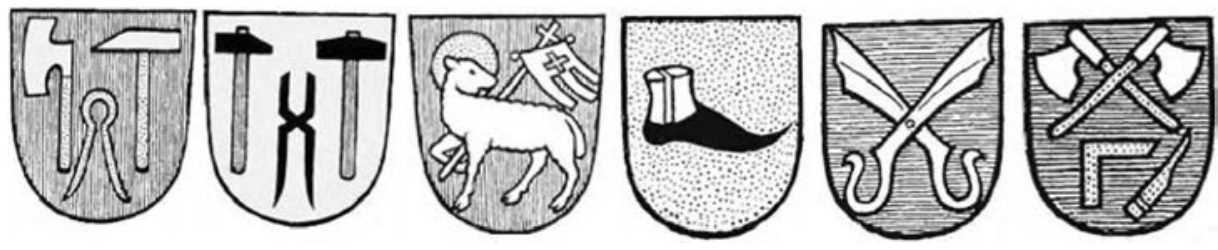

Figura 17. Marcas de corporaciones profesionales un tanto heraldizadas fechadas en 1415.

Se trata de marcas definidas mediante algún utensilio de uso en el gremio.

Por orden: canteros, herreros, carniceros, zapateros, sastres y carpinteros de la ciudad de Basilea (Suiza).
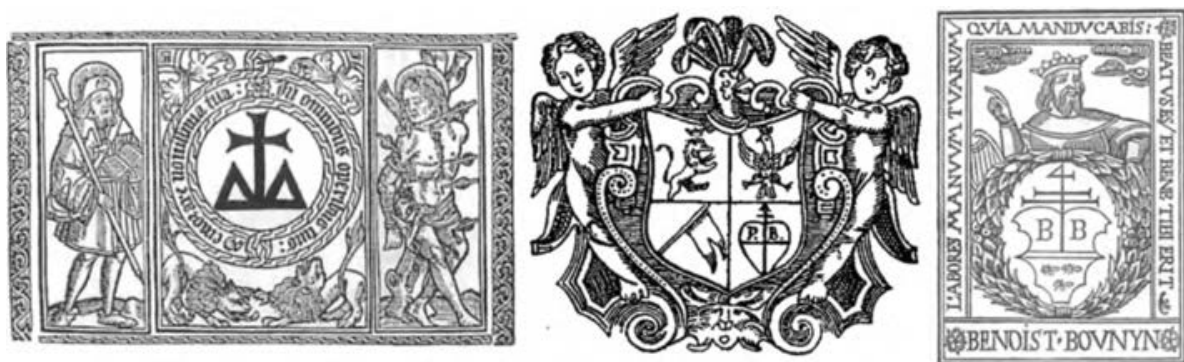

Figura 18. De izquierda a derecha: marca heraldizada del impresor alemán Joan Hurus, del impresor zaragozano Pascual Bueno y, por último, del impresor francés Benoist Bounyn.

- Marcas abstractas: en muchos casos creadas a partir de una estructura geométrica (figura 16).

- Marcas heraldizadas: pueden ser de los grupos superiores (identificativas, onomásticas o abstractas) en las cuales se ha implementado la marca en un escudo (figura 18).

- Marcas simbólicas: se trata de marcas que pueden o no estar heraldizadas. En cualquier caso, trabaja con símbolos de carácter religioso o esotérico que complementan otros datos gráficos relativos a actividades profesionales (figura 18).

Las imágenes de marcas heraldizadas (figura 18) muestran dos variantes. El escudo del impresor zaragozano Pascual Bueno contiene claramente su marca geometrizante dentro del cuartel del blasón y prácticamente todos elementos de un heraldo, como los tenantes y el timbre. Los dos ejemplos incluyen elementos de carácter simbólico, como es el caso de la marca del impresor alemán Joan Hurus, la cual está flanqueada por las figuras de Santiago y san Sebastián. La marca del impresor francés Benoist Bounyn contiene la figura del rey David y una corona de laurel. 

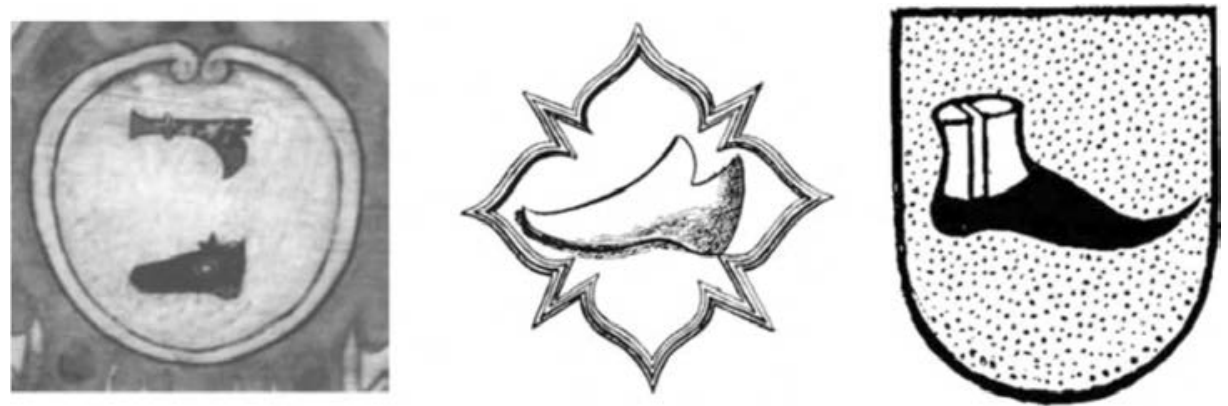

Figura 19. De izquierda a derecha: Villa Inca de Mallorca (siglos XV-Xvi), Palma de Mallorca (siglos Xıv-Xv) y Basilea (año 1415). Vemos cómo son coincidentes iconográficamente, aunque con variaciones gráficas en la representación, por ejemplo, en la forma y el estilo del escudo.

Hay que reseñar que las marcas identificativas de carácter representativo, como las que aparecen en la figura 17 , adquieren rápidamente un carácter homogéneo en toda Europa, como es el caso de Suiza, Países Bajos, Alemania, Inglaterra y España 7

Esto se debe, como sucede hoy en día, a que se trata de formas sencillas que permiten reconocer fácilmente el objeto y asociarlo a la actividad profesional de uso. Lo que hace que las marcas gremiales que definen este tipo de sectores trasciendan fronteras. Así, vemos cómo en ciudades de diferentes países utilizan la representación de un pez, o peces y arpones, para el gremio de pescadores; unas tijeras abiertas, los sastres; martillos, escoplos y compases son empleados por los gremios de carpinteros y albañiles; un cordero pascual o un san Juan nimbado, los carniceros; pinzas y martillos los herreros; un zapato, los zapateros. Aun así, observamos cómo gráficamente muestran formas de representación distintas dependiendo del lugar y época. No obstante, estas variantes pueden asociarse a un estilismo específico de la zona, por lo que debe ser analizado con mayor profundidad, aunque no hemos hallado excesiva información.

\subsection{BRISADO DE ESCUdOS PARA PERPETUAR LA HERENCIA PROFESIONAL-FAMILIAR}

Como en el caso de los blasones familiares de carácter feudal o real, las familias realizan variaciones en sus marcas con el fin de hacer sobrevivir la marca de honor de sus antepasados. Esto es, brisaban sus escudos imitando la costumbre

7 Martínez Llorente (2012) indica que «[L]a heráldica profesional llegará a asumir con el tiempo una formulación iconográfica de formas casi idénticas que trascenderá fronteras». 

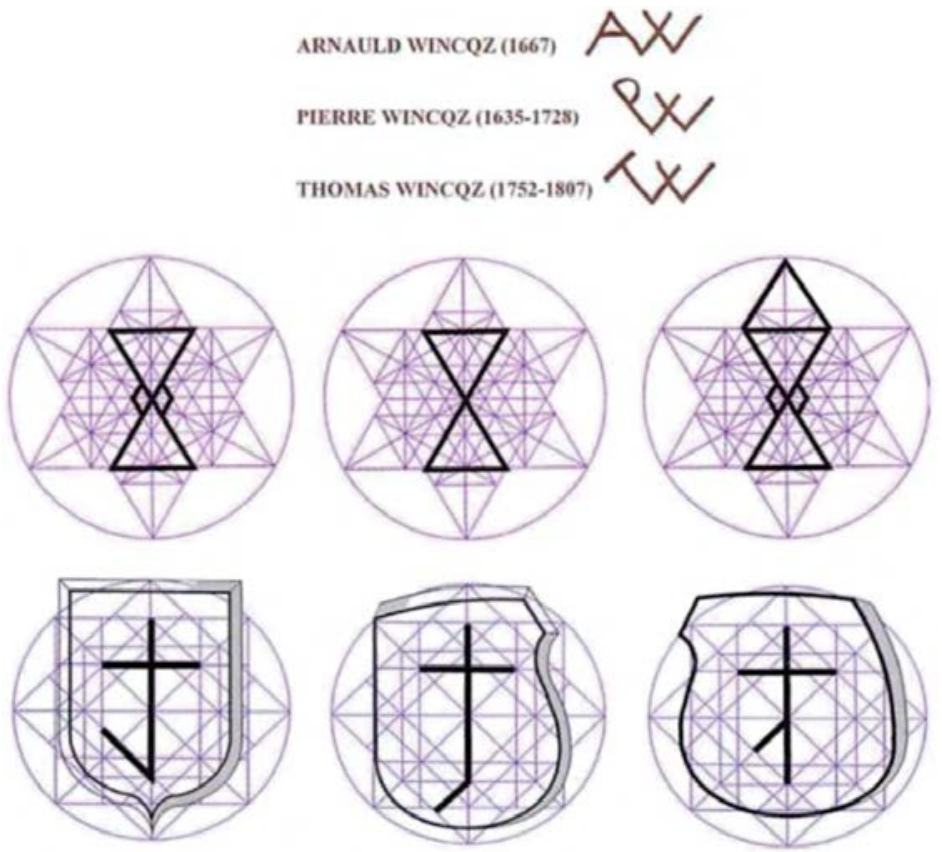

Figura 20. Superior: marcas de la familia Wincpz, maestros canteros de Gante, muestran brisuras en marcas de tipo onomástico. Central: marcas de la familia Lechien, maestros canteros, muestran brisuras en marcas de geométrico en red ad triangulum.

Inferior: marca de Conrad Roritzer, Mathias hijo y Wolfgan nieto, maestros de obras en Ratisbona, muestran brisuras en marcas de tipo geométrico red ad cuadratum y en escudos.

nobiliaria (Ramírez Barberó 1986, 145). Habitualmente los hijos eran aprendices de los padres y proseguían con las actividades profesionales, con la experiencia y con el arte del progenitor, dando fe de sus conocimientos y de la antigüedad de su estirpe. Estas variantes se insertaban en los escudos y en las marcas personales. Así se observa una variante en el diseño que diferenciaba a padres e hijos o ramas familiares. Dentro de este grupo vemos variantes en marcas abstractas y onomásticas. 

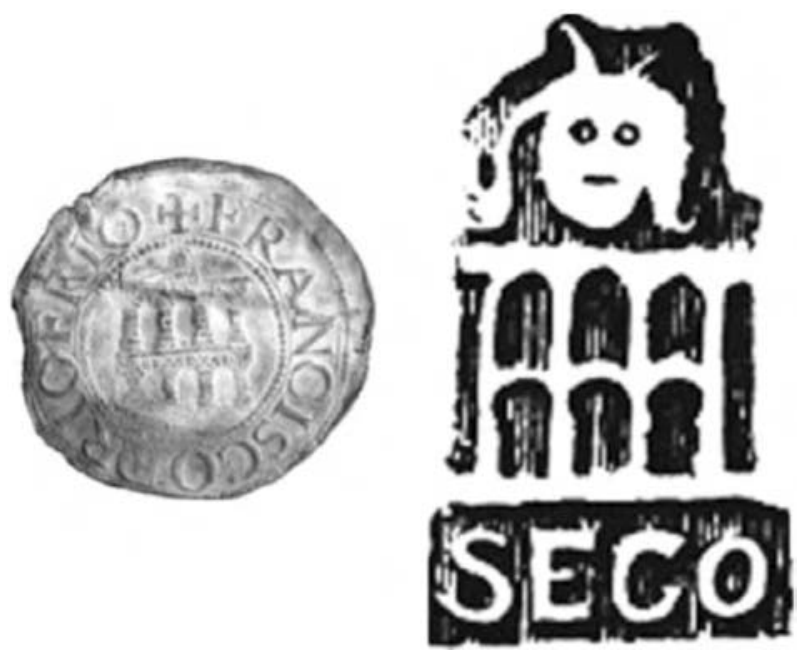

Figura 21. Dos ejemplos de marcas o emblemas gremiales que incluyen las armas de la ciudad. Marca de pañero segoviano acuñada en moneda y marca de platero de Segovia, ambas de siglo xv. Observamos cómo incluyen el símbolo emblemático de la ciudad, el acueducto romano, que sigue siéndolo hoy en día.

\section{MARCAS GREMIALES REPRESENTADAS CON LAS ARMAS DE LA CIUDAD DE ORIGEN}

Con respecto a la ciudad de origen encontramos que es obligado incluir en su marca o emblema las armas de la ciudad donde es labrada, como en el caso de los plateros españoles de la Corona de Castilla ${ }^{8}$. Esta disposición afectará a otros grupos gremiales como los de brocados, sedas o paños (Martínez Llorente 2012). Esto nos remite a las dimensiones de la marca actual en la que la dimensión de país de origen es un parámetro en muchos casos determinante (Aaker 2002), así como a condicionamientos culturales por los que se puede ver afectada la marca (McCracken, 1993). Debido a que el origen de marca en muchos gremios o familias era de gran relevancia por su calidad profesional, en muchos casos la marca de honor se asociaba a las armas de la ciudad, dotando de valores positivos al emblema familiar-gremial. Así, a la marca como signo de autoría (Alvarado 2009) se le suma la estrecha relación del gremio con la población y el lugar donde se asienta (Martínez Llorente 2012).

${ }^{8}$ La disposición de Juan II (1405-1454) aprobada en las Cortes de Madrid el año 1435 dicta lo siguiente: «El platero que labre plata sea obligado de tener una seńal conocida, para poner debajo de la señal que hiciere para tener debajo del marco de la tal ciudad o villa do se labrare dicha plata». 

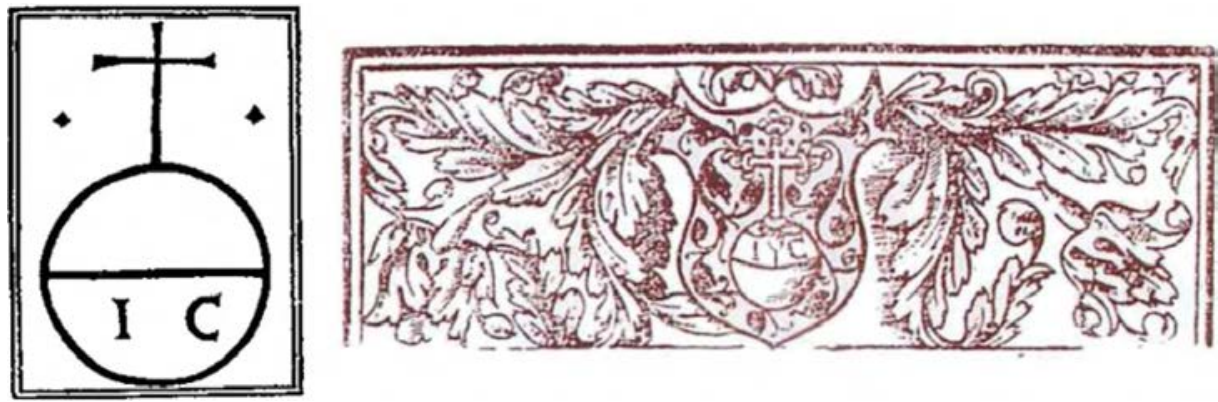

Figura 22. Marca geometrizante (1527) y marca heraldizada (1537) del impresor Juan Cromberger.
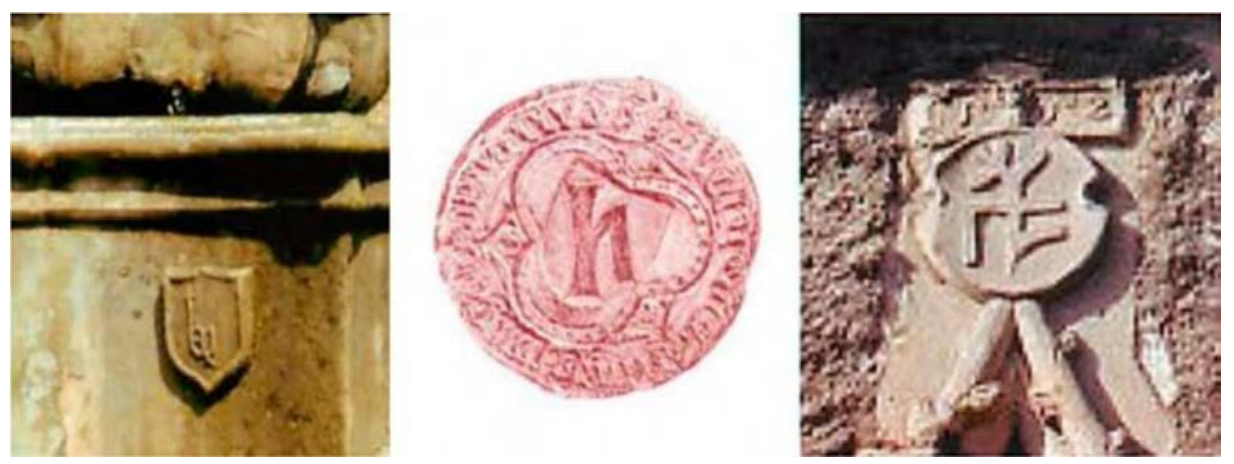

Figura 23. Izquierda: escudo con marca onomástica (dos iniciales) que se encuentra en el claustro del monasterio de San Jerónimo de la Murtra, en Badalona, siglo xv. Central: sello de marca heraldizada del maestro de obras Ulrich von Ensingen en la catedral de Estrasburgo. Derecha: marca heraldizada de maestro de obras ubicada en el dintel de la puerta de la iglesia de San Esteban de Osterwieck, siglo Xv.

\section{MARCAS PROFESIONALES SIN ELEMENTOS HERÁLDICOS Y MARCAS DE HONOR}

En este periodo muchos maestros de oficios hacían coincidir las marcas profesionales simples junto con marcas de honor (Alvarado 2009, 150). Hay que clarificar que las marcas de honor, a diferencia de las marcas "normales», contenían elementos gráficos relativos a la dignidad y el honor del oficio. Así, la marca geometrizante, onomástica o identificativa era colocada en un escudo y "adornada» con elementos simbólicos o heráldicos bajo una presentación heraldizada.

Vemos un ejemplo de variación en la marca de Juan Cromberger, donde la marca geometrizante está diseñada en la cruz sobre un círculo dividido en el que se insertan en la zona inferior las iniciales del impresor. La versión heraldizada se presenta, sin embargo, como marca de honor relacionando los elementos heráldicos 
del diseño con atributos de honor y con la dignidad del oficio. En este caso se aprecia una búsqueda de asociar la calidad y el rigor del oficio del impresor a la marca, dotando a la marca de elementos culturalmente asentados en la época como son los valores del honor, la rigurosidad o la calidad. Se entiende, pues, que se trata de un proceso de imitación de los escudos de armas de las casas nobiliarias.

Vemos que se origina un proceso de blasonado de las marcas personales que se expande a las marcas de las corporaciones de oficios. En el caso de las marcas geometrizantes adquiere su punto de desarrollo entre los siglos XIV-XV, coincidiendo con la asociación de los blasones a hazañas del portador, y confiriendo de este modo como una especie de currículum a su portador a nivel social.

En este contexto las marcas de honor son insertadas en todo tipo de soportes. Los maestros canteros las esculpen en piedras de edificaciones (rosetones, dinteles...), así como en monedas, cerámicas o sellos para la firma de contratos, dotándolas de carácter legal. En estos casos representan una forma primitiva de las marcas actuales, que confieren a los objetos que las poseen todos los atributos y cualidades del fabricante, por ejemplo, la marca bordada o impresa en las prendas.

\section{CONCLUSIONES}

En la Edad Media se produce un avance en la comunicación y desarrollo gráfico que con posterioridad afectará a un sector realmente moderno y que está asociado a la evolución de las urbes y a la necesidad de abastecer con productos a la incipiente clase media. La aparición de grupos de poder en lucha hace que se desarrolle en Europa la heráldica, un sistema de signos y colores que codifican información relativa a un individuo, una familia o un grupo de poder y que, en última instancia, será asimilado por sectores económicos como método que regule su comunicación. Supone un sistema bien codificado y regulado que define unas directrices constructivas gráficas, tanto en la marca como en el resto de los elementos donde se aplica.

Así, se observa que la gestación de las marcas actuales tiene su origen, en gran medida, en la Edad Media. Periodo en el que ya se aprecian variantes constructivas en las que predominan características simbólicas, heraldizadas, identificativas, abstractas u onomásticas, como se pueden encontrar en la actualidad. Lo que sugiere un sistema anterior a la constitución del registro de marcas. Este hecho se afianza en las marcas identificativas, que adquieren un carácter uniformizado en toda Europa. Como sucede en la actualidad, trasciende fronteras, ya que se recurre a formas sencillas de fácil reconocimiento gráfico que permiten diferenciar la especialización de cada gremio, aunque con variantes estilísticas en cada zona. Por otro lado, se afianza la idea de un empleo sistemático de matrices que ayudan a la construcción de las marcas y, como sucede hoy en día, con el uso de cuadrículas y otros métodos de organización espacial que ayudan a ordenar y generar las formas gráficas. El sistema llevado a la comunicación de gremios supone un modelo efervescente de comunicación que será aplicado por fabricantes, productores y en los sectores profesionales. 


\section{BIBLIOGRAFÍA}

Aaker, D. 2002 [1996]. Construir Marcas Poderosas. Barcelona: Ediciones Gestión 2000.

Aldazaval y Murguía, P.J. 1773. Compendio heráldico arte de escudos de armas según el methodo mas arreglado del blasón, y Autores españoles. Pamplona: viuda Martin Josep de Rada.

Alvarado Planas, J. 2009. Heráldica, simbolismo y usos tradicionales de las corporaciones de oficios: las marcas de canteros. Madrid: Ediciones Hidalguía.

Costa, J. 2009. La imagen de marca. Barcelona: Editorial Paidós, Paidós Diseño 02.

Eco, U. 1988 [1973]. Signo. Barcelona: Ediciones Labor.

Fuster, R. y Aguadé, J.2017. «Las marcas de cantería dentro del contexto de la arquitectura medieval: proporción y mesura», en Las marcas de cantería dentro del contexto de la arquitectura medieval, una primera aproximación. Madrid: Círculo de Bellas Artes. 1-48.

Grandmaison, C. 1852. Dictionnaire héraldique. Paris: Petit-Montrouge.

Martínez Llorente, F. 2012. «La heráldica profesional o la formulación de un nuevo imaginario emblemático y heráldico", Emblemata (18): 181-242.

McCracken, G. 1993. "The value of the brand: an anthropological perspective», en Brand Equity and Advertising, de D.A. Aaker y A.L. Biel. NJ: Lawrence Erlbaum Associates, Hillsdale.

Medvedev, Mikhail Y. 2012. «El Diseño Heráldico», Emblemata (18): 99-108.

Montaner Frutos, A. 2012. «Identificación, evocación y conformación en los emblemas heráldicos: el caso de las armas parlantes", Emblemata (18): 41-70.

Piferrer, F. 1855 . Tratado de heráldica y blasón, adornado con láminas. Madrid: Ramón Campuzano.

Pirenne, H. 1975. Historia económica y social de la Edad Media. México: Fondo de Cultura Económica.

RAMírez y BARberó, J.T. 1986. Las variantes de los signos lapidarios como brisuras heráldicas. Pontevedra: Editorial Diputación de Pontevedra.

Rzıнa, F. 1993. Études sur les marques de tailleurs de Pierre. Francia: Éd. de la Maisnie-Trédaniel, Dieulefit: la Nef de Salomon; Éditions Véga.

VAN Belle, Jean-Louis. 2001. «Signes graves, signes écrits, signes reproduits», SIGNO. Revista de Historia de la Cultura Escrita (Universidad de Alcalá), 211-247. 
